\title{
Distribution and release of human pancreatic polypeptide
}

\author{
T. E. ADRIAN, S. R. BLOOM, M. G. BRYANT, J. M. POLAK, PH. HEITZ, AND \\ A. J. BARNES
}

From the Department of Medicine and Histochemistry, Royal Postgraduate Medical School, London

SUMMARY A simple and reliable radioimmunoassay has been developed for a new gut hormone, HPP. In the primate $93 \%$ of the total PP was found in the pancreas with a small amount throughout the remaining gastrointestinal tract. HPP has been shown to be produced by a number of pancreatic apudomas and their metastases. The immunoreactive PP from these tumours and from normal pancreas was chromatographically indistinguishable from the pure peptide. The plasma PP concentration rose rapidly after a meal in normal subjects and was still raised six hours later. Fasting plasma PP levels in patients with PP cell containing pancreatic endocrine tumours were higher than even the postprandial level in normal subjects. PP measurement is thus useful in diagnosis of pancreatic endocrine tumours.

In the course of purifying chicken insulin Kimmel extracted and purified a 36 amino acid, straight chain, peptide which he named avian pancreatic polypeptide (Kimmel et al., 1971). Chance isolated a similar peptide from bovine pancreas (BPP) and subsequently the pig (PPP), sheep (OPP), and man (HPP) (Lin and Chance, 1974a). These latter three peptides differ from BPP in only one or two amino acid residues at positions 2, 6, or 23 (Lin and Chance, 1974b). PP has been detected by immunofluorescence to occur in specific endocrine cells of the pancreas and intestine and has been found to have a wide spectrum of pharmacological actions on the gastrointestinal tract (Lin and Chance, 1974b).

HPP is present in high concentration in human endocrine neoplasms of the pancreas and in metastases of such tumours (Polak et al., 1976). Plasma concentrations of HPP were also found to be raised in patients whose tumours produced the peptide (Floyd et al., 1975; Polak et al., 1976). The distribution of PP has not been previously reported, although reference has been made to the finding of PP cells in the intestines of some species (Larrson et al., 1975). Furthermore, there is no information on the possible multiple molecular forms of PP. We have investigated these problems and also established the normal fasting PP levels in man and the response to a meal.

Received for publication 26 July 1976

\section{Methods}

RADIOIMMUNOASSAY

Antisera against human pancreatic polypeptide were produced in rabbits by subcutaneous and intramuscular injection at multiple sites of $1 \mathrm{mg}$ PP in complete Freund's adjuvant, with booster injections in incomplete Freund's adjuvant $(0.5 \mathrm{mg}$ PP per rabbit). Standards for the assay were prepared from pure HPP and were lyophilised and stored at $-20^{\circ} \mathrm{C}$.

Labelled 125I HPP, with a specific activity of approximately $200 \mu \mathrm{Ci} / \mu \mathrm{g}$, was prepared by a modification of the conventional chloramine $\mathrm{T}$ method (Hunter and Greenwood, 1962): $1 \mu \mathrm{g}$ of pure HPP was iodinated with $0.5 \mu \mathrm{Ci}$ carrier free $\mathrm{Na}{ }^{125 \mathrm{I}}$ using $20 \mu \mathrm{g}$ chloramine $\mathrm{T}$ in $0.04 \mathrm{ml}$ phosphate buffer $\mathrm{pH} 7 \cdot 4$ for 15 seconds at room temperature. The reaction was stopped by the addition of $48 \mu \mathrm{g}$ sodium metabisulphite and $500 \mu \mathrm{l}$ $1 \%$ potassium iodide was added before gel filtration on Sephadex G.50 fine. The product was eluted from a $60 \mathrm{~cm}$ column with $0.1 \mathrm{M}$ formic acid, containing $1 \%$ human serum albumin and $1 \%$ Trasylol at a rate of $7.0 \mathrm{ml} / \mathrm{h}$.

Duplicate $0.8 \mathrm{ml}$ assay tubes were set up containing $200 \mu \mathrm{l}$ plasma. Antisera was added to give a final dilution of $1.560,000$ and bound $50 \%$ of the $20 \mathrm{pg}$ HPP ${ }^{125}$ I label. Standards were made up in hormone free plasma prepared by a charcoal 940 
extraction procedure (Albano et al., 1972). After an incubation period of seven days at $4^{\circ} \mathrm{C}$, antibody bound label was separated from free by the addition of $0.5 \mathrm{ml}$ of a $4 \%$ charcoal slurry coated with $0.4 \%$ dextran. All dilutions were in $0.5 \mathrm{M} \mathrm{pH} \mathrm{8.0} \mathrm{Veronal}$ buffer.

\section{DISTRIBUTION}

The distribution of HPP in the alimentary tract was investigated in three adult baboons and two monkeys, which had been maintained on human diet for several years. The intestines were removed and after rapid division into anatomical regions they were immediately plunged into freezing acid ethanol. The tissue was stored at $-20^{\circ} \mathrm{C}$ until time of extraction when individual regions were weighed and extracted four times with $5 \mathrm{ml}, 4 \mathrm{ml}, 3 \mathrm{ml}$, and, finally, $2 \mathrm{ml}$ acid ethanol per gram of tissue. After centrifugation, the tissue debris was discarded, the supernatants pooled and neutralised with ammonia. The peptide liquors were dried down under nitrogen to remove the ethanol and redissolved in buffer before assay.

The same antisera were used for histochemical studies using an indirect immunofluorescence technique, Polak et al. (1976).

\section{NORMAL PANCREAS AND TUMOURS}

Tumour and normal pancreas tissue removed at various operations were immediately frozen, and stored at $-20^{\circ} \mathrm{C}$. Samples of tissue for extraction were later boiled for 10 minutes in distilled water (5 ml per gram tissue). The water extract was removed by centrifugation and acidified by addition of formic acid to $0 \cdot 1 \mathrm{M}$. The solid material was rehomogenised in a fresh solution of $0 \cdot 1 \mathrm{M}$ formic acid. After a further homogenisation the three extracts were pooled, recentrifuged, and stored at $-20^{\circ} \mathrm{C}$

\section{COLUMN CHARACTERISATION}

Extracts from primary tumour (VIPoma), liver metastases (glucagonoma), baboon pancreas, and normal human pancreas were eluted from a $90 \mathrm{~cm}$ Sephadex G50 superfine gel column and compared with pure HPP. The column was run in $0.1 \mathrm{M}$ formic acid at $7 \mathrm{ml} / \mathrm{h}$ and calibrated with human serum albumin, Trasylol, 125I VIP, 125I glucagon, and phenylalanine. These markers were also mixed with each extract before loading to ensure consistency of the operational column.

\section{SUBJECTS}

Blood samples were taken in aprotinin (Trasylol), a proteolytic enzyme inhibitor, $(9 \mathrm{ml}$ blood to $1 \mathrm{ml}$ Trasylol $10000 \mathrm{KIU} / \mathrm{ml}$ ) in a heparinised tube, centrifuged, plasma decanted, and frozen within 15 minutes. Fasting blood samples were taken from 25 healthy subjects aged 21-53 years (mean 31 years) who were of normal weight and height. Seven of these volunteers ate a conventional hospital lunch consisting of $79 \mathrm{~g}$ carbohydrate, $28 \mathrm{~g}$ protein, and $44 \mathrm{~g}$ fat (830 calories). Fasting blood samples were also taken from three patients who had undergone total pancreatectomy.

\section{Results}

ASSAY

The HPP label gave an excess antibody binding of above $90 \%$ and was extremely stable, being usable in the assay for over three months. No displacement of labelled HPP from antibody was observed with $1 \mathrm{ng}$ added insulin, glucagon, gastrin, VIP, GIP, or motilin. The assay detected changes between adjacent samples of $6 \mathrm{pmol} / 1$ plasma with $95 \%$ confidence. The intra-assay precision was $5.7 \%$ $(\mathrm{n}=10)$ and inter-assay precision $10 \cdot 2 \%(\mathrm{n}=6)$.

\section{DISTRIBUTION}

The distribution of PP in the higher primate can be seen in Fig. 1. Small amounts of PP immuno-

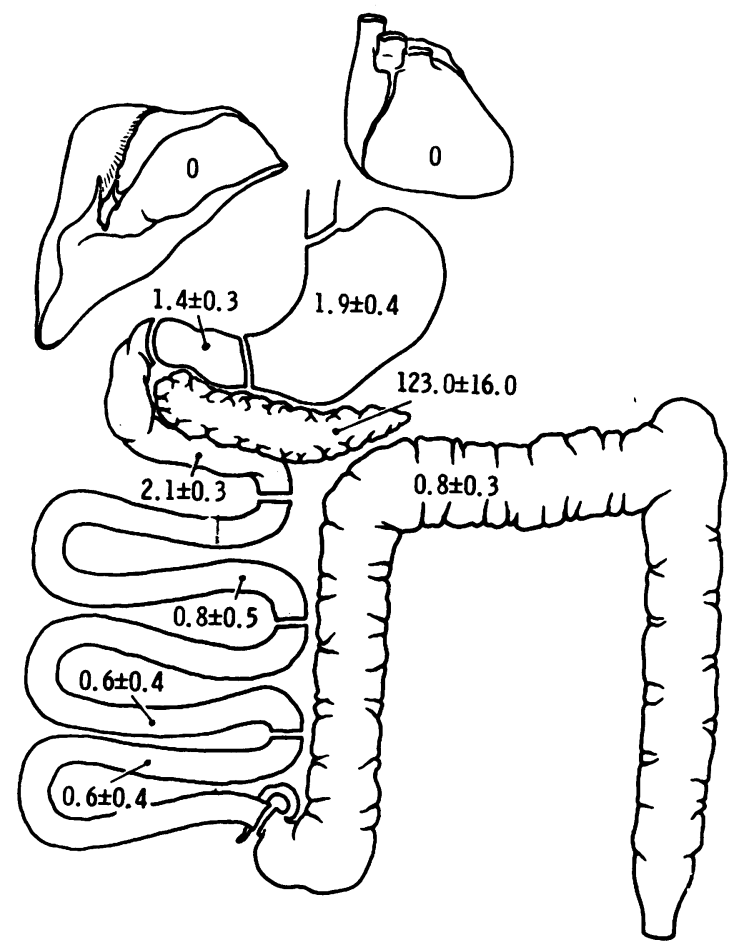

Fig. 1 Concentration of PP in the primate in pmol/g wet weight of whole bowel. 
reactivity are found throughout the intestinal tract from the oesophagus to the colon but none is detectable in heart, liver, lungs, or brain. The pancreas has approximately $93 \%$ of the total PP in the gut, with a concentration of $123 \mathrm{pmol} / \mathrm{g}$ wet tissue. This correlates well with histochemical findings, as PP cells outside the pancreas appear to be extremely sparsely distributed. Pancreatic PP cells are very occasionally found in the periphery of the islets but are mainly found in clumps between the acinar cells (Fig. 2).

\section{TUMOURS}

HPP has been shown to be produced by a number of pancreatic endocrine tumours and their metastases (Polak et al., 1976). The apudomas investigated were insulinomas, glucagonomas, gastrinomas, and VIPomas. The mean tumour PP content of neoplasms containing PP cells was 2600 pmol compared with $390 \mathrm{pmol} / \mathrm{g}$ in normal human pancreas. The plasma concentration of $\mathrm{PP}$ in the positive tumour cases was $>300 \mathrm{pmol} / 1$ compared with the normal subjects, $2-90 \mathrm{pmol} / 1$.

It can be seen in Fig. 3 that there was only a single peak of PP immunoreactivity in extracts of primary VIPoma, liver secondary, glucagonoma, normal human pancreas, and baboon pancreas and that the PP immunoreactivity in these extracts appears to have an identical gel elution pattern.

PLASMA ASSAYS

The mean fasting plasma HPP level of 25 normal

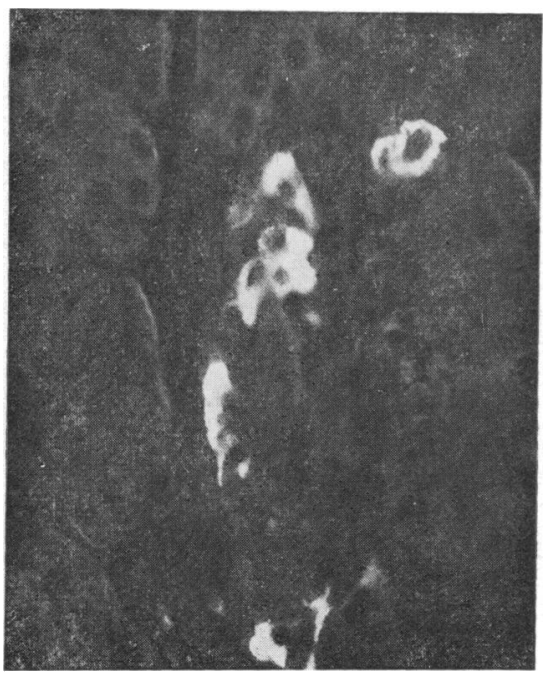

Fig. 2 Group of PP cells in the pancreatic exocrine parenchyma. $\times 283$ subjects was $31 \cdot 2 \mathrm{pmol} / 1$ (SE 6.2) range $2-90 \mathrm{pmol} / 1$.

The rise after a normal hospital lunch in seven normal subjects is seen in Fig. 4. The 30 minute peak in postprandial plasma HPP was $164 \mathrm{pmol} / \mathrm{l}$ (SE 46.2). The plasma PP level six hours after the meal was eaten was still raised at $80 \cdot 1 \mathrm{pmol} / \mathrm{l}$ SE 26.6).

In fasting plasma from patients who had undergone total pancreatectomy PP was undetectable $(<6 \mathrm{pmol} / \mathrm{l})$.

\section{Discussion}

The role of pancreatic polypeptide in normal physiology has not as yet been elucidated, although from infusion studies in the dog (Lin and Chance, 1974a), the actions opposing CCK-PZ (relaxation of the gall bladder and inhibition of pancreatic enzyme and juice flow) are the most likely to be physiological. The development of a sensitive and specific assay is a prerequisite for the establishment of true hormonal status for this new gut peptide.

PP is detectable throughout the intestinal tract of the primate, although in very much lower concentration than in the pancreas. The postprandial rise in PP is of the same order of magnitude in molar terms as that of insulin, but levels remain high for several hours. It seems likely that the pancreatic PP is responsible for most of this rise. This introduces a possible new component to the well known enteropancreatic endocrine axis. The small amount of PP in the rest of the alimentary tract may possibly be of importance postprandially but plasma from patients who have undergone total pancreatectomy have no detectable PP, suggesting that, at least in the fasting state, the extrapancreatic component of the total gut PP does not contribute significantly. PP from pancreatic apudomas, a liver secondary, and normal human and baboon pancreas were all indistinguishable from pure HPP in elution pattern from a high resolution, calibrated gel column, only a single peak being detected. Thus, in the sources so far investigated, there appears to be only one molecular species. The peptides from tumours and normal pancreas were identical or very similar to the pure hormone.

Much information about the normal actions of hormones has in the past been extrapolated from the study of endocrine tumours producing these hormones. This is unfortunately not yet possible with PP as a pure 'PPoma' has still to be described. However, it is evident that PP cells are commonly present in other pancreatic apudomas and their metastases. The marked and well-known clinical characteristics of these tumours may well mask the effect of overproduction of PP. Plasma PP measure- 


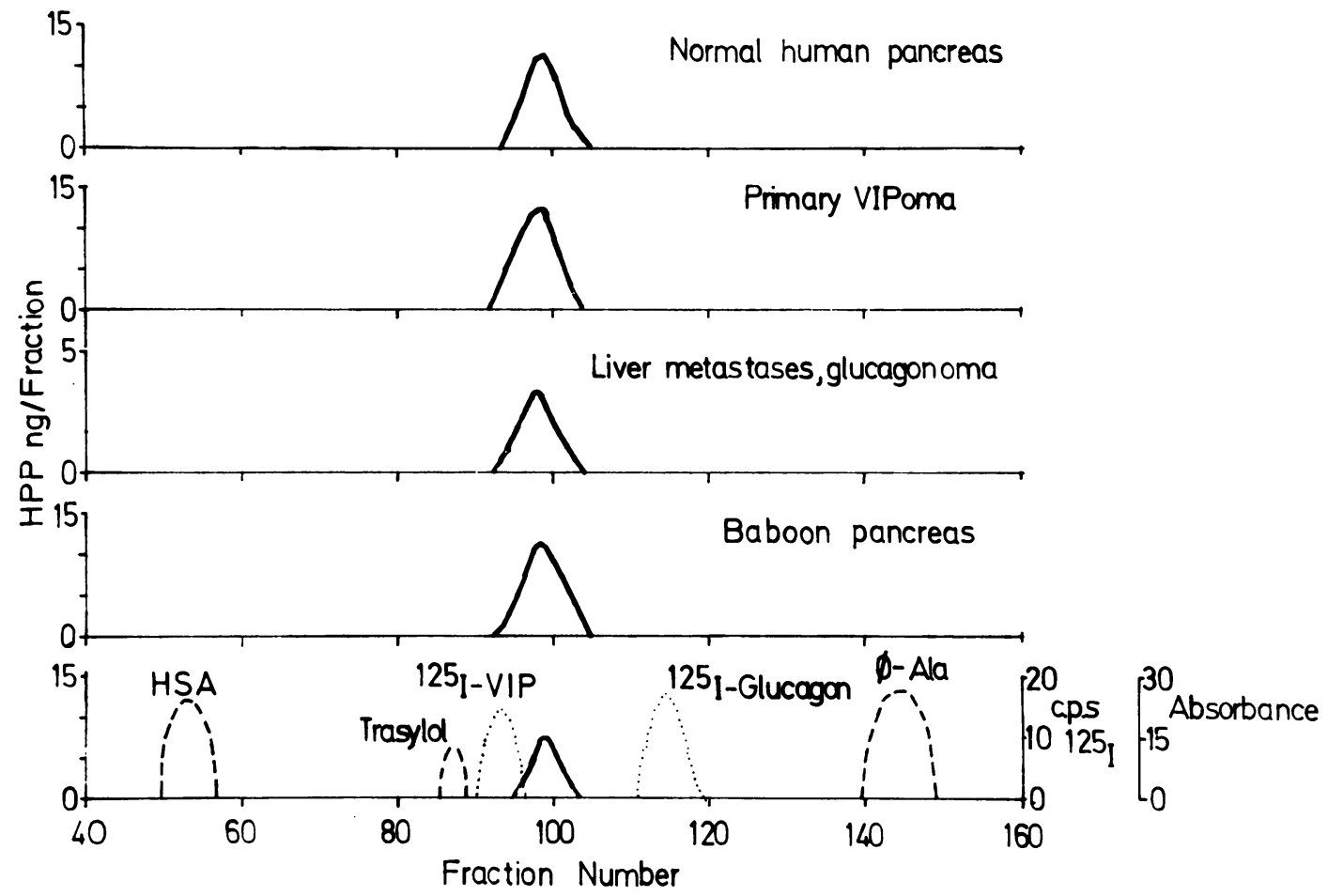

Fig. 3 Gel chromatography pattern of PP immunoreactivity.

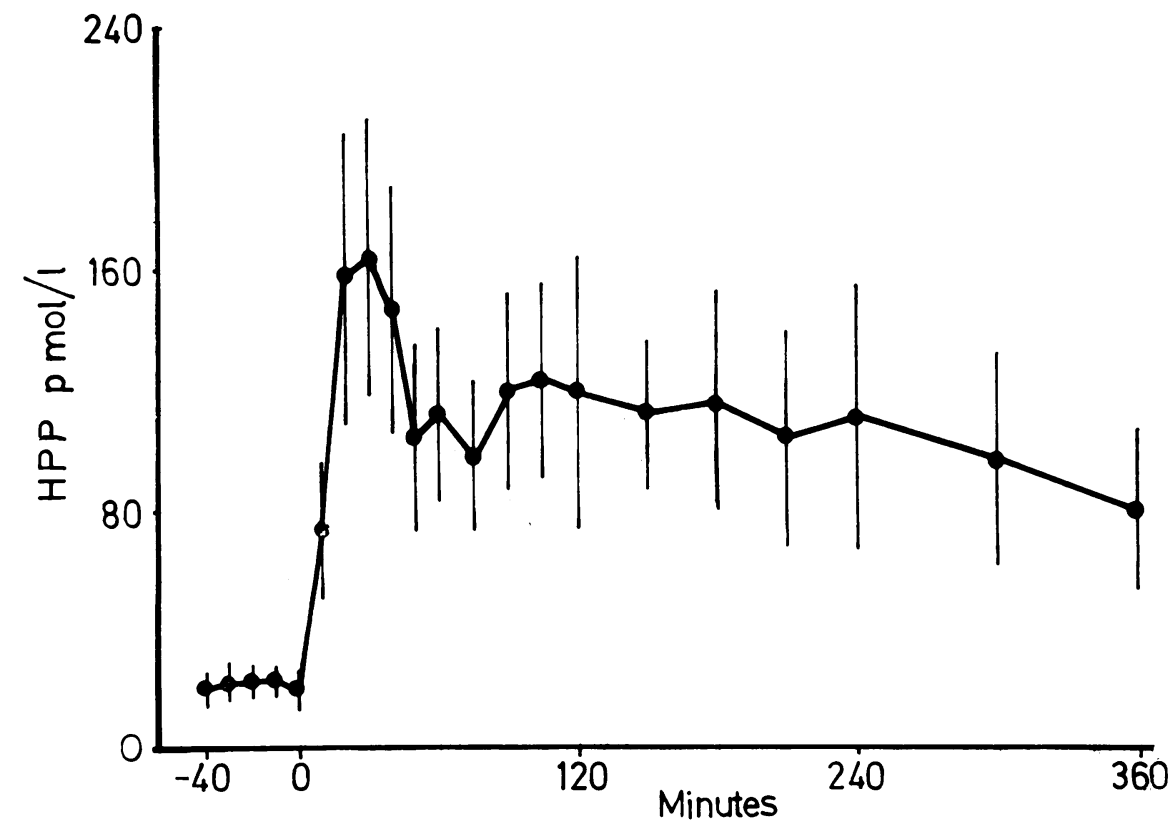

Fig. 4 Plasma PP concentration after a normal meal in seven volunteers. 
ment clearly has an important role in the diagnosis and perhaps monitoring of treatment in patients with pancreatic endocrine tumours, who are often treated only after long delay because of diagnostic difficulties. A non-specific marker for such tumours would be of considerable value if measured in conjunction with the hormone 'specifically' produced by the tumour. The straightforward nature of the radioimmunoassay for HPP makes it a very suitable tool for routine use in the diagnosis of these tumours. The development of a radioimmunoassay for human PP has demonstrated that this hormonal peptide, which is found almost solely in the pancreas, is released in very significant quantities after a normal meal. It has also shown an interesting and useful new facet of pancreatic tumour pathology. Clearly much additional work is required to clarify PP's true physiological role.

Pure pancreatic polypeptide and its antibodies were generously donated by $\operatorname{Dr} \mathrm{R}$. E. Chance and Mrs Nancy E. Moon (Lilly Research Laboratories, Eli Lilly and Co, Indianapolis, Ind, USA). Philipp Heitz, MD, is on leave from the Department of Pathology, University of Basel, supported by a grant of the Swiss National Academy of Medical Sciences.

\section{References}

Albano, J. D. M., Ekins, R. P., and Turner, R. C. (1972). A sensitive, precise radioimmunoassay of serum insulin relying on charcoal separation of bound and free hormone moieties. Acta Endocrinologica, 70, 487-509.

Floyd, J. C., Chance, R. E., Hayashi, M., Moon, N. E., and Fajans, S. S. (1975). Concentrations of a newly recognised pancreatic islet polypeptide in plasma of healthy subjects and in plasma and tumours of patients with insulinsecreting islet cell tumours. Clinical Research, 23, 535A.

Hunter, W. M., and Greenwood, F. C. (1962). Preparation of iodine-131 labelled human growth hormone of high specific activity. Nature, 194, 495-496.

Kimmel, J. R., Pollock, H. G., and Hazelwood, R. L. (1971). A new pancreatic polypeptide hormone. Federation Proceedings, 30, 1318. (Abstract).

Larrson, L. I., Sundler, F., and Hakanson, R. (1976). Pancreatic polypeptide-a postulated new hormone: Identification of its cellular storage site by light and electron microscopic immunocytochemistry. (Personal communication).

Lin, T. M., and Chance, R. E. (1974a). Gastrointestinal actions of a new bovine pancreatic polypeptide. In Endocrinology of the Gut, pp. 143-145. Edited by W. Y. Chey and F. P. Brooks. C. R. Slack; Thorofare, New Jersey.

Lin, T. M., and Chance, R. E. (1974b). Candidate hormones of the gut. VI. Bovine pancreatic polypeptide (BPP) and avian pancreatic polypeptide (APP). Gastroenterology, 67, 737-738.

Polak, J. M., Bloom, S. R., Adrian, T. E., Heitz, P., Bryant, M. G., and Pearse, A. G. E. (1976). Pancreatic polypeptide in insulinomas, gastrinomas, vipomas and glucagonomas. Lancet, 1, 328-330. 